\title{
Optimized Ratiometric Fluorescent Probes by \\ Peptide Self-assembly
}

Yanbin Cai, ${ }^{\dagger,}{ }^{\dagger}$ Jie Zhan, ${ }^{+}$Haosheng Shen,${ }^{\ddagger}$ Duo Mao, ${ }^{\dagger}$ Shenglu Ji, ${ }^{\ddagger}$ Ruihua Liu, ${ }^{+}$Bing

Yang, ${ }^{\ddagger}$ Deling Kong, ${ }^{\ddagger}$ Ling Wang, ${ }^{*,+}$ Zhimou Yang ${ }^{*,+,}$

+State Key Laboratory of Medicinal Chemical Biology, College of Pharmacy, and Tianjin Key Laboratory of Molecular Drug Research, ${ }^{\ddagger}$ Key Laboratory of Bioactive Materials, Ministry of Education, College of Life Sciences, and Collaborative Innovation Center of Chemical Science and Engineering (Tianjin), Nankai University, Tianjin 300071, P. R. China

Email: yangzm@nankai.edu.cn and chwling@ nankai.edu.cn

\section{Experimental supporting information}

\section{Synthesis and Characterization}

Compounds $1 \boldsymbol{a}$ and $2 \boldsymbol{a}$ were synthesized according to Scheme S-1

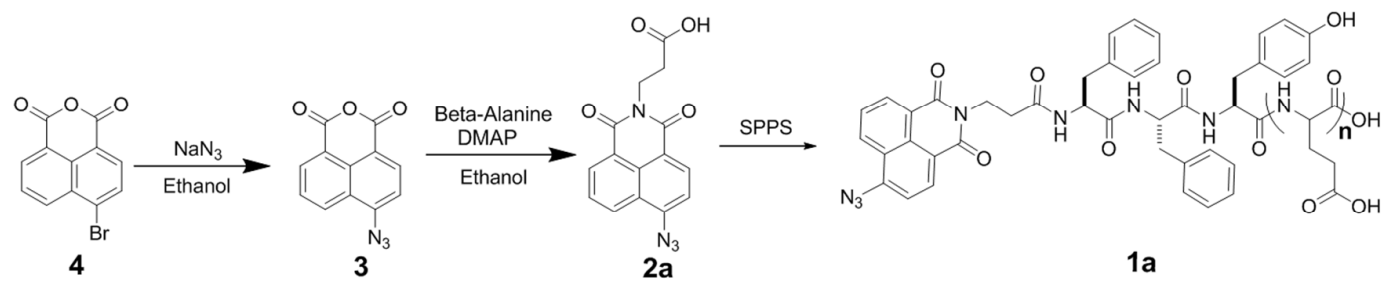

Scheme $\mathbf{S - 1}$. Synthetic route of Compound $1 a$ and $2 a$.

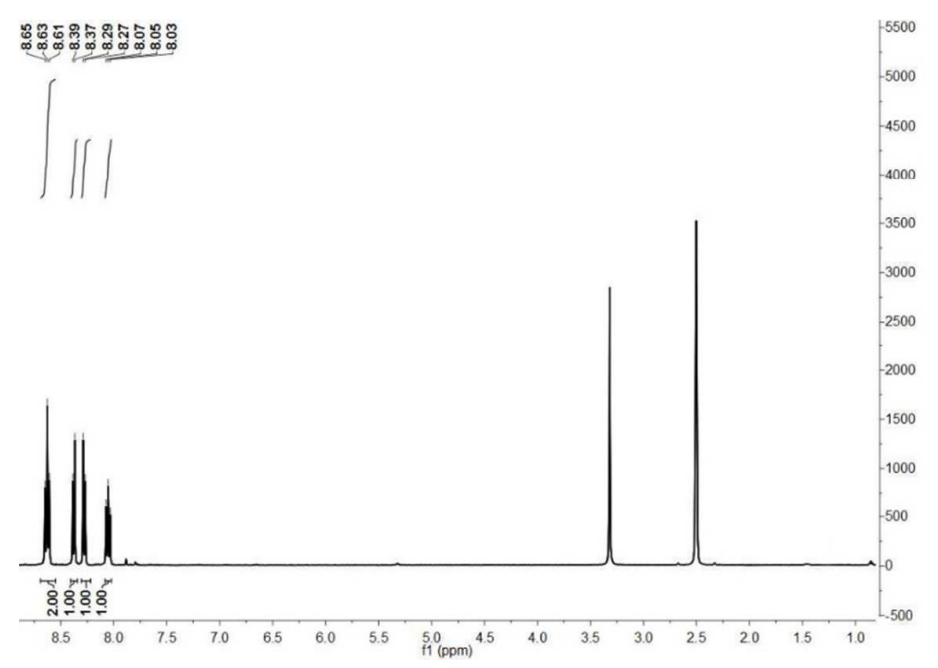

Figure $\mathbf{S}-1 .{ }^{1} \mathrm{H}$ NMR of compound 3 

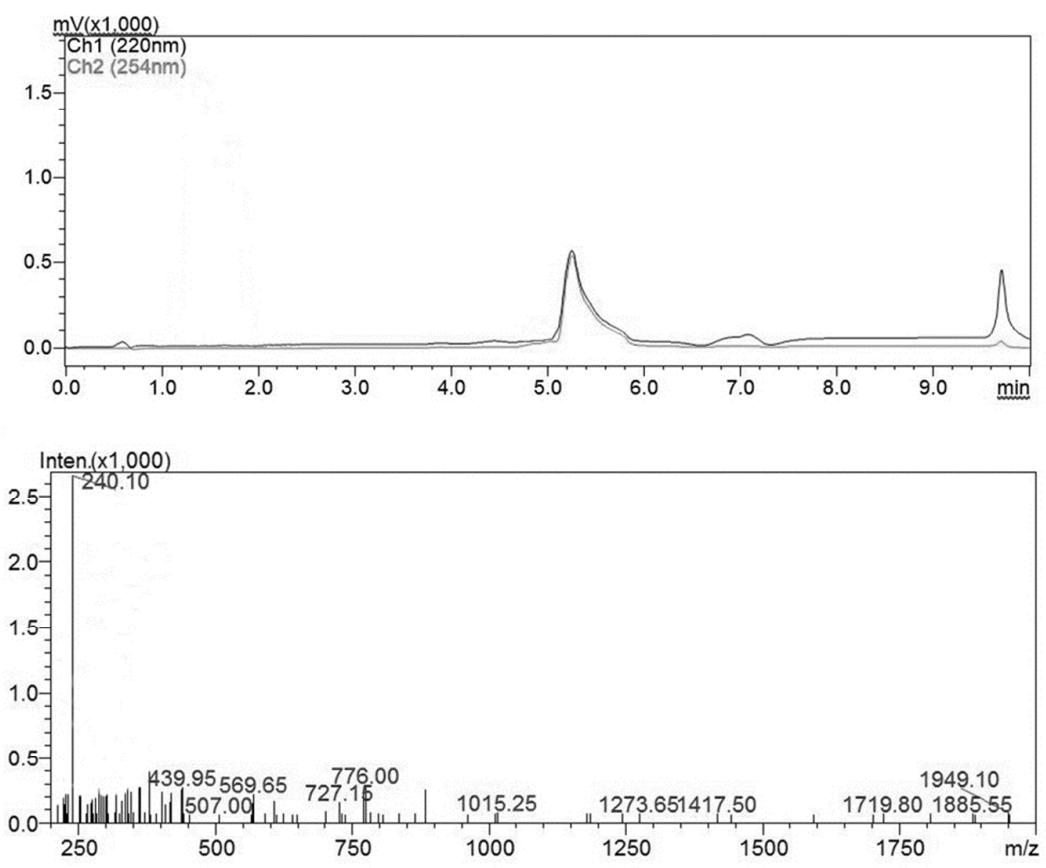

Figure S-2. LC-MS of compound 3

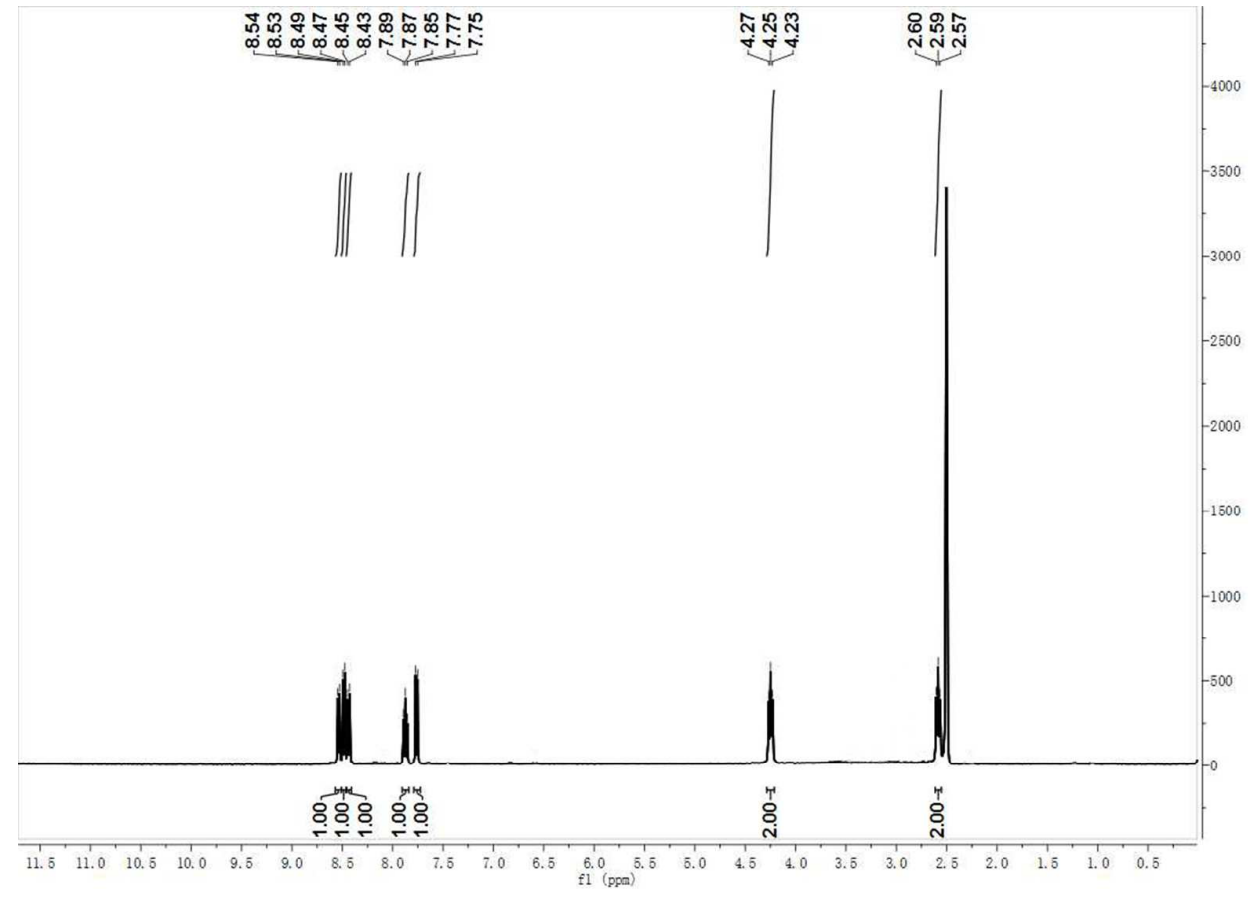

Figure $\boldsymbol{S}$-3. ${ }^{1} \mathrm{H}$ NMR of compound $2 \boldsymbol{a}$. 

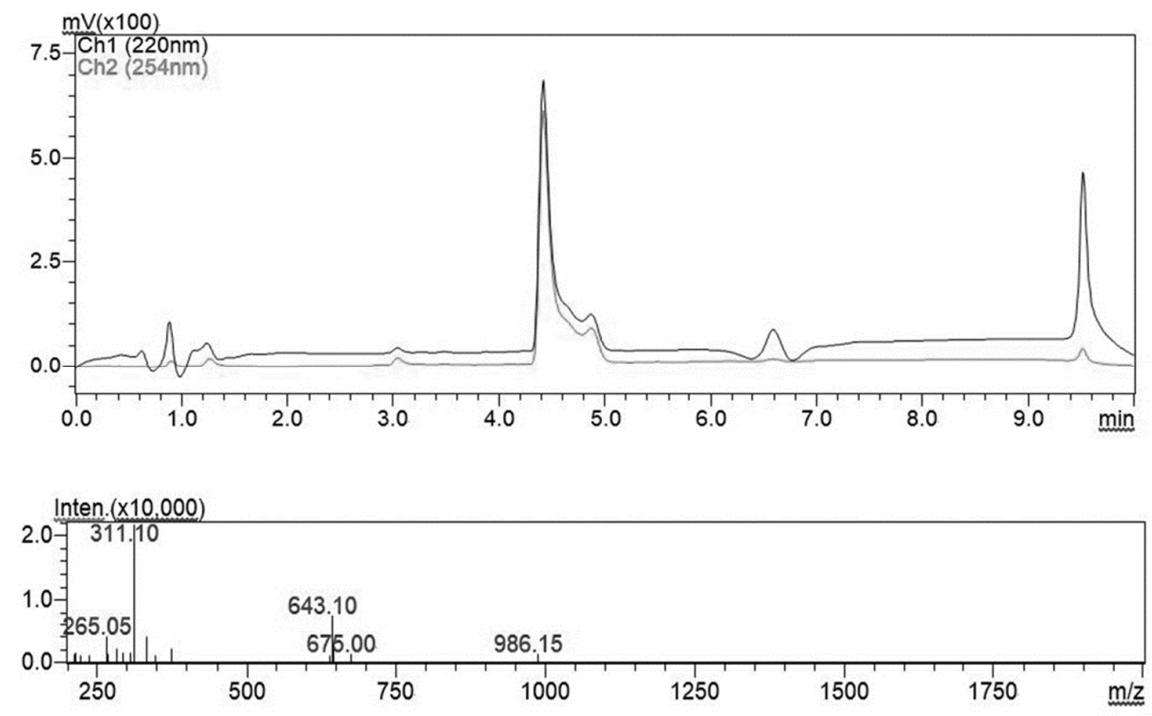

Figure 5 -4. LC-MS of compound $2 a$

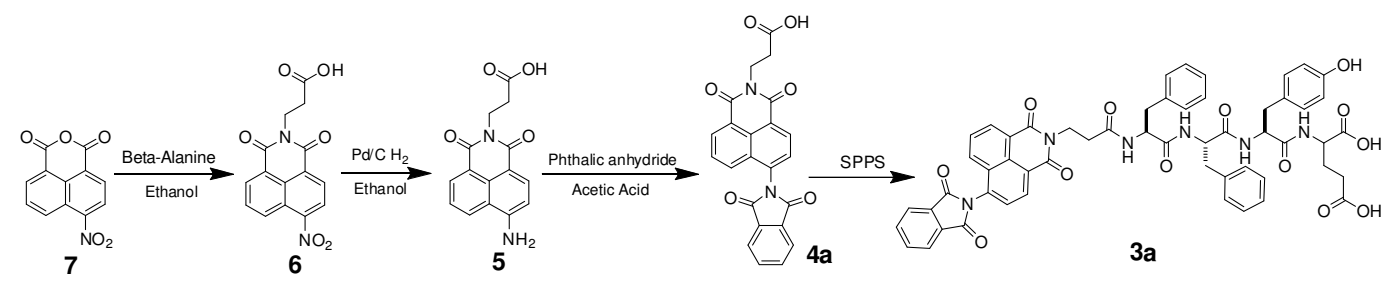

Scheme $\mathbf{S - 2}$. Synthetic route of Compound $3 a$ and $4 a$. 


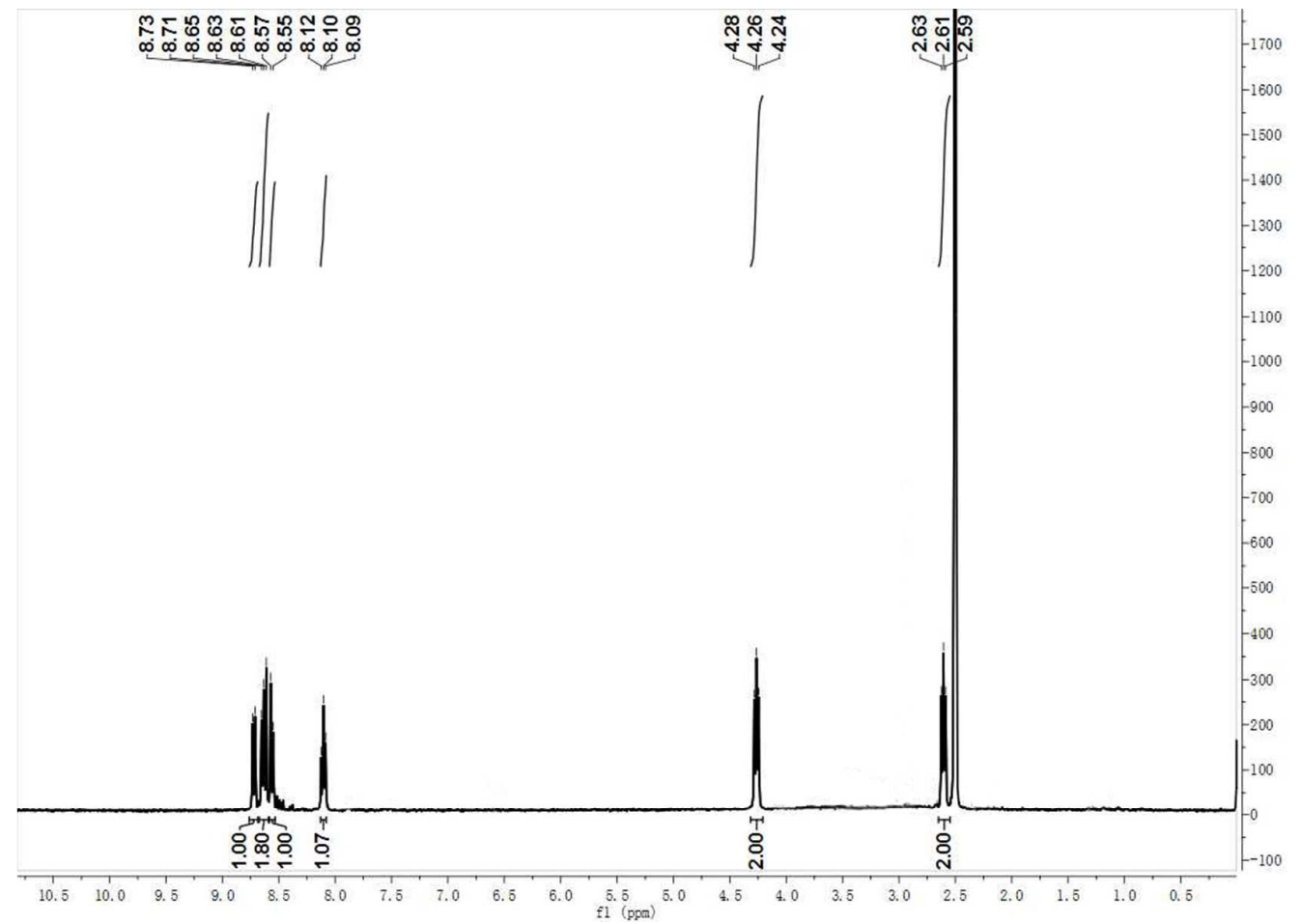

Figure $S-5 .{ }^{1} \mathrm{H}$ NMR of compound 6.
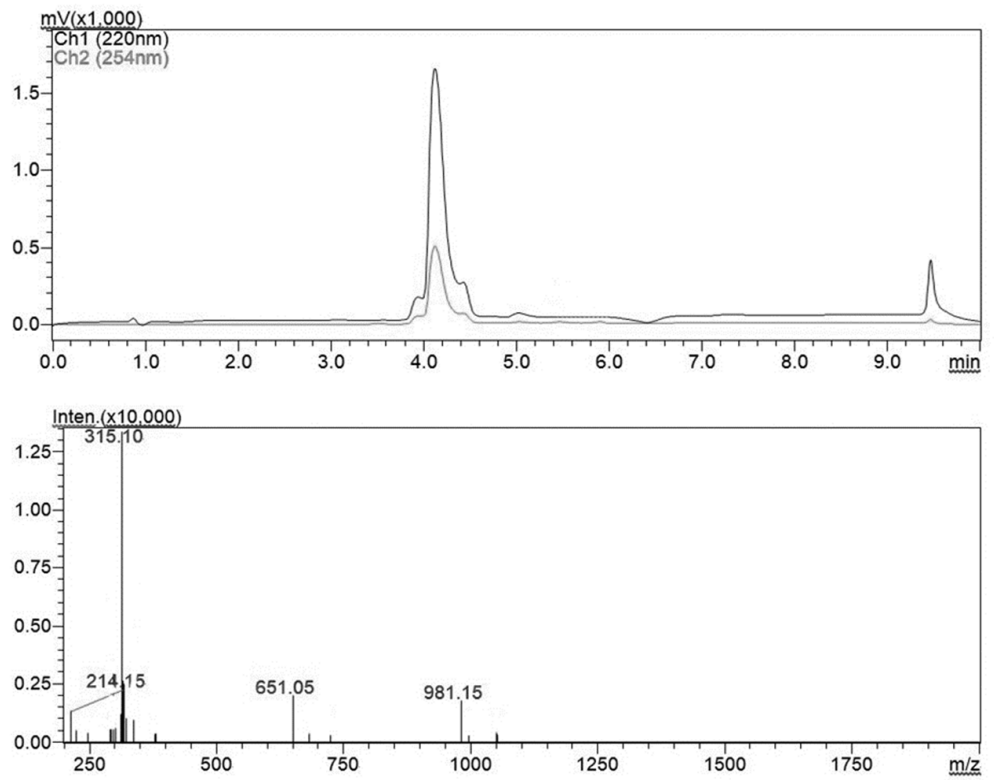

Figure S-6. LC-MS of 6 


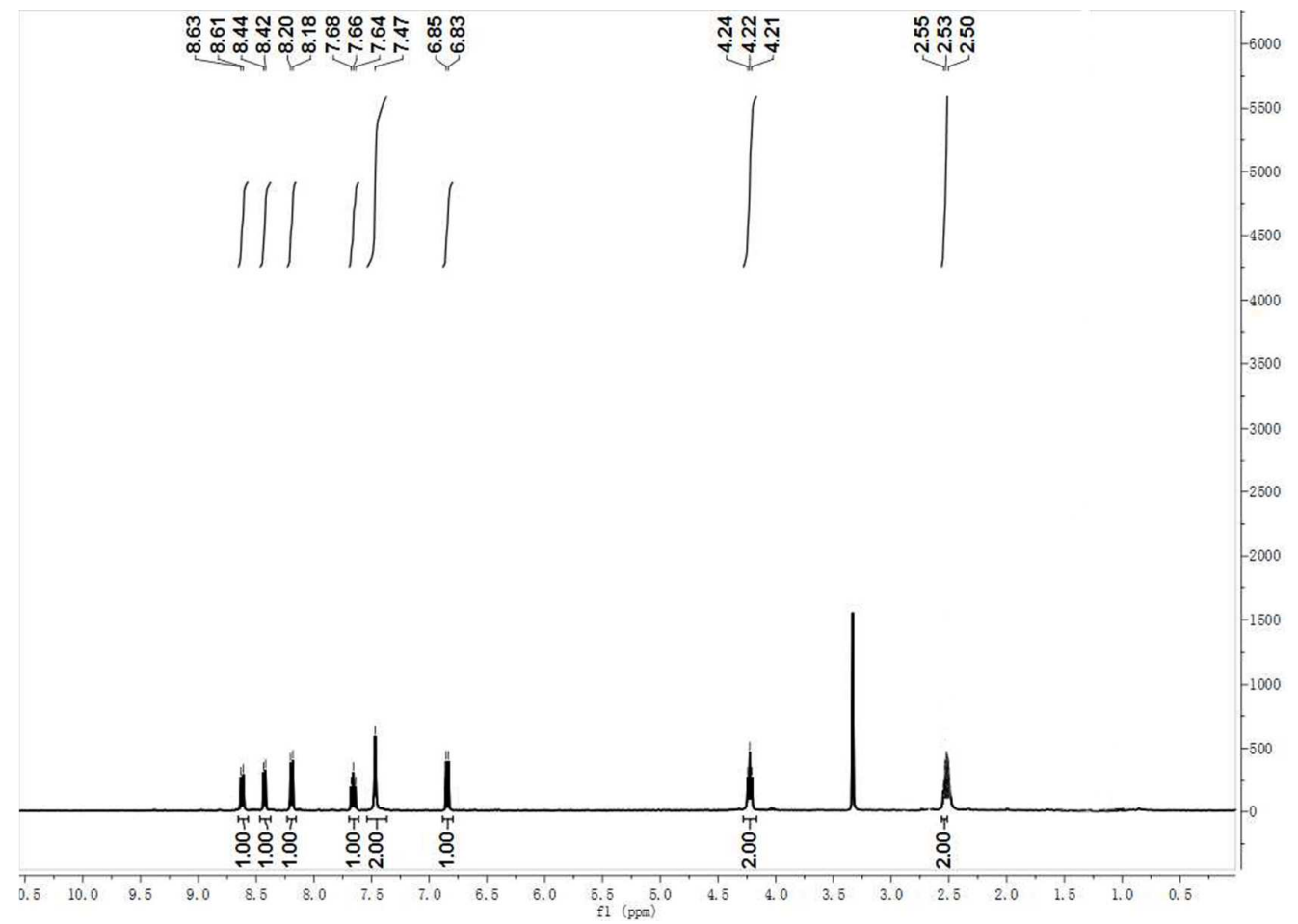

Figure S-7. ${ }^{1} \mathrm{H}$ NMR of compound 5.
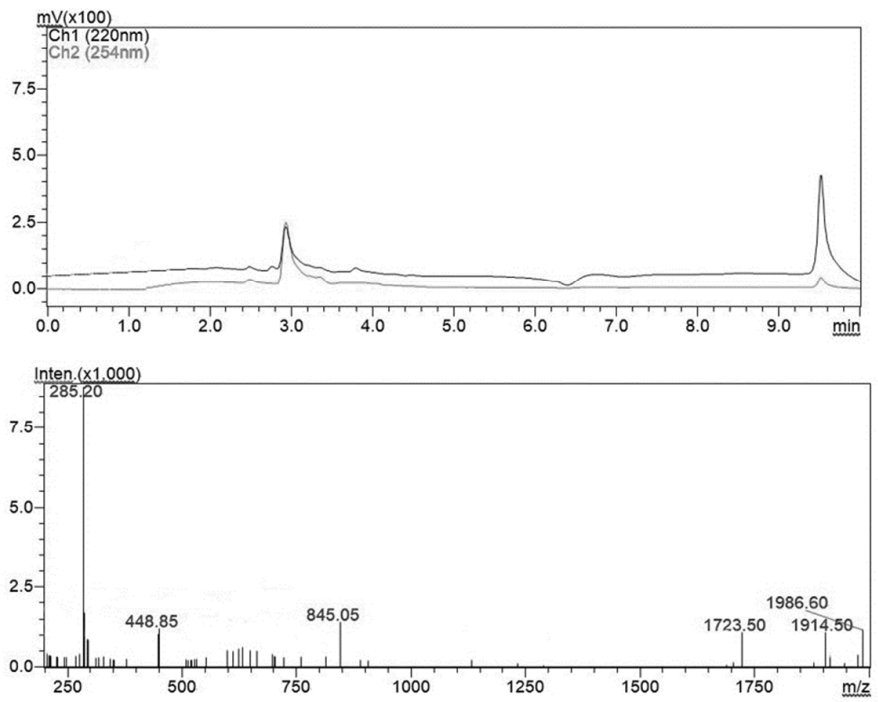

Figure $S-8$. LC-MS of 5 


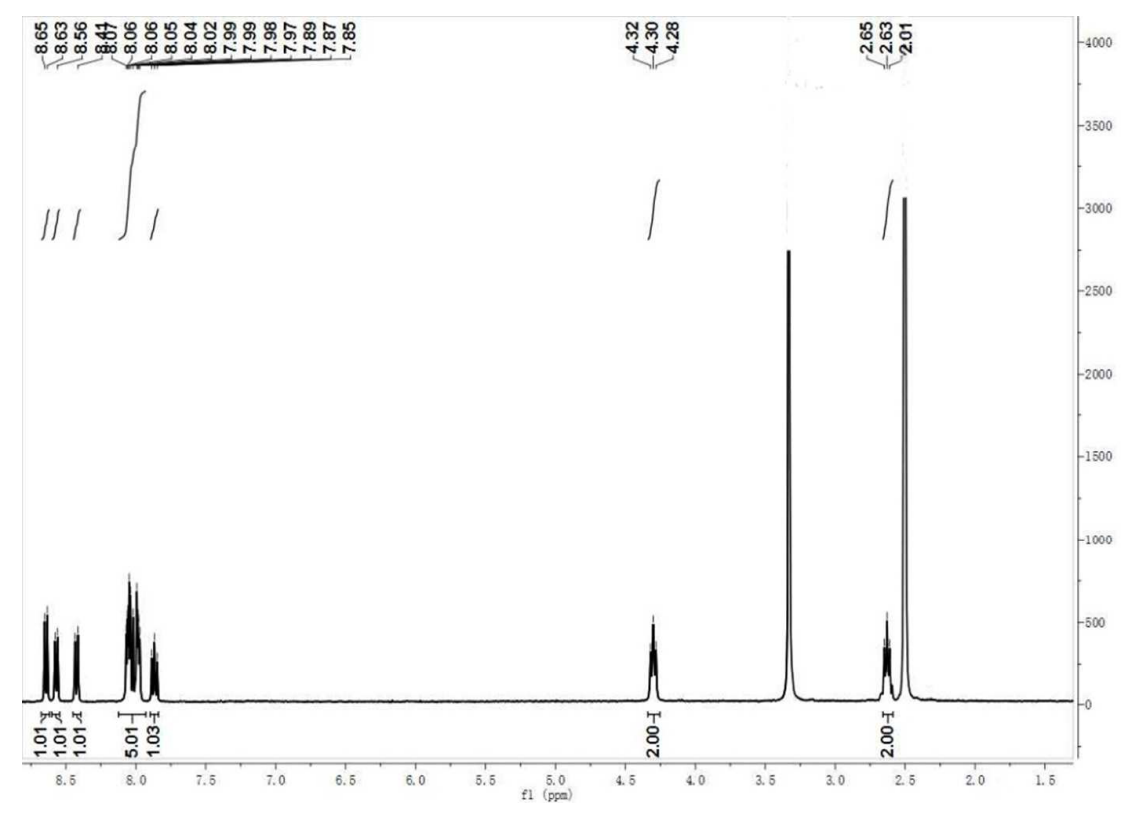

Figure $\boldsymbol{S}$-9. ${ }^{1} \mathrm{H}$ NMR of compound $\mathbf{4 a}$.

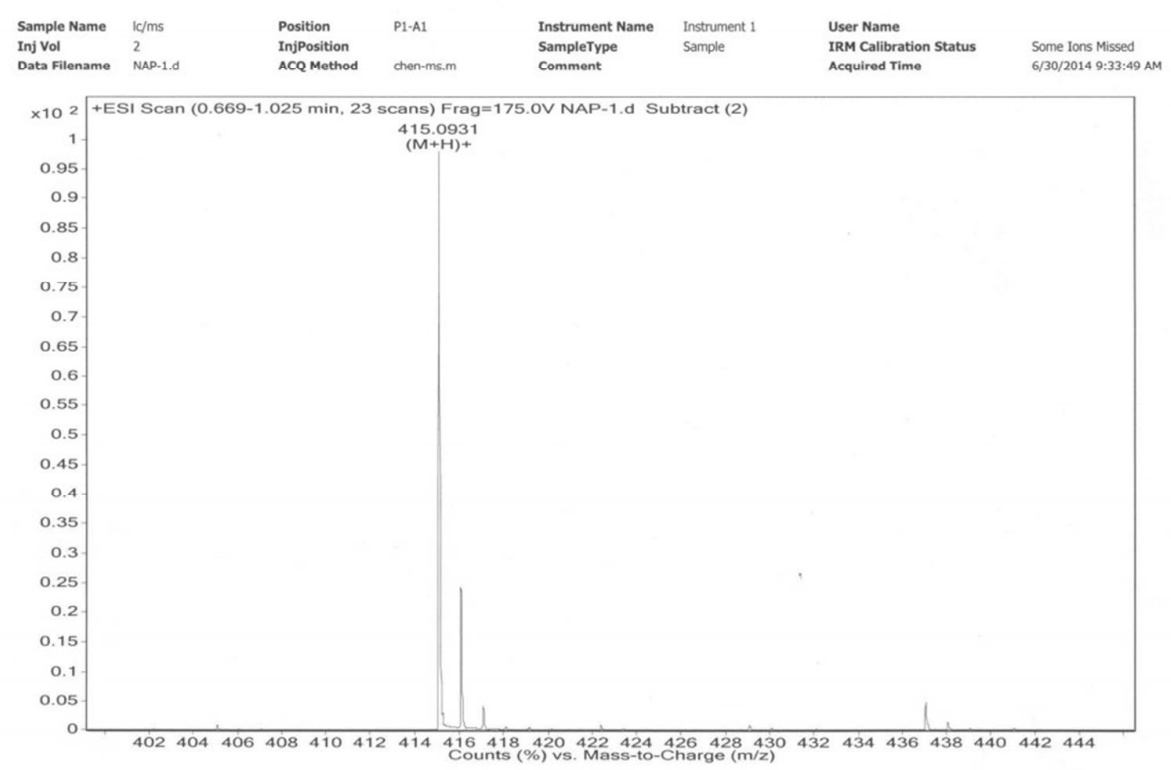

Figure $S$-10. HR-MS of $4 a$ 


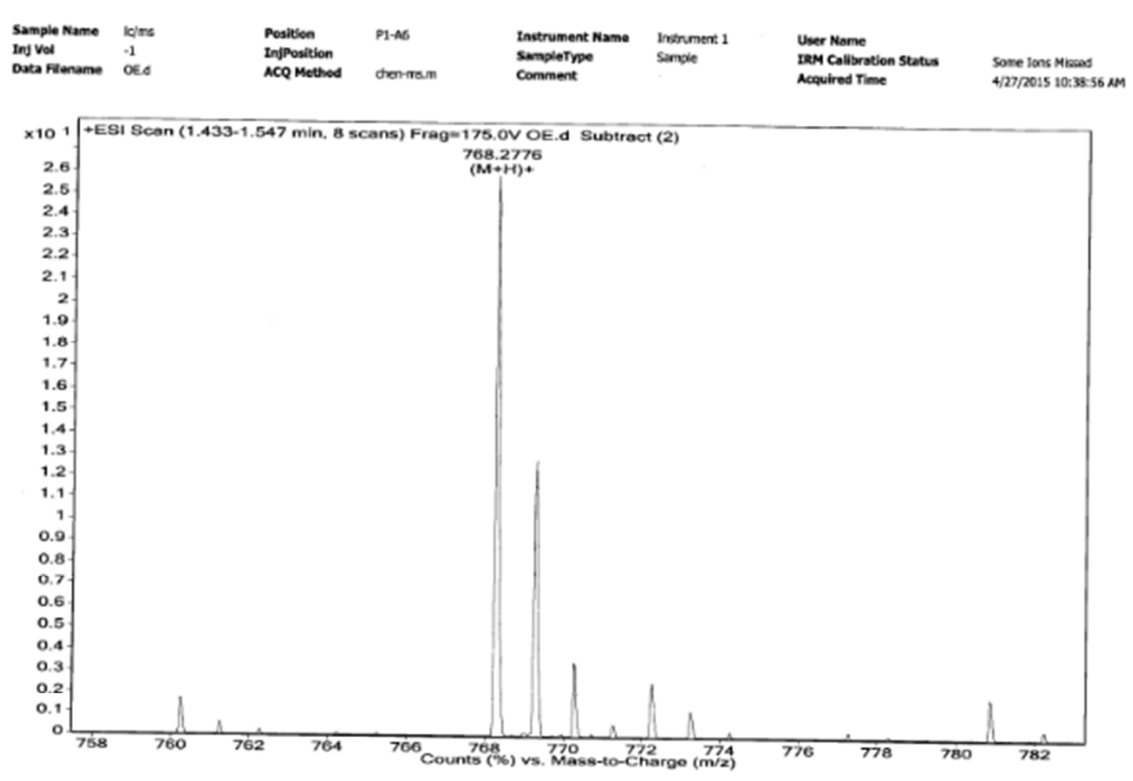

Figure S-11. HR-MS of $\mathrm{N}_{3}$-NTI-FFY

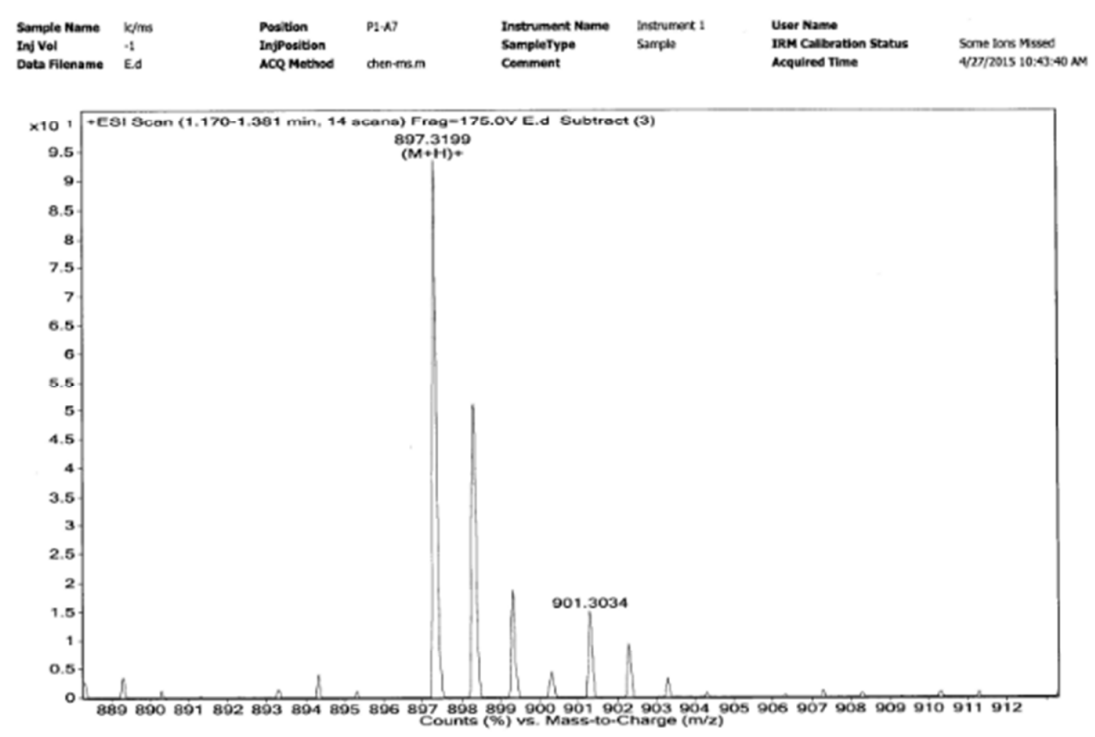

Figure S-12.HR-MS of $\mathrm{N}_{3}$-NTI-FFYE 

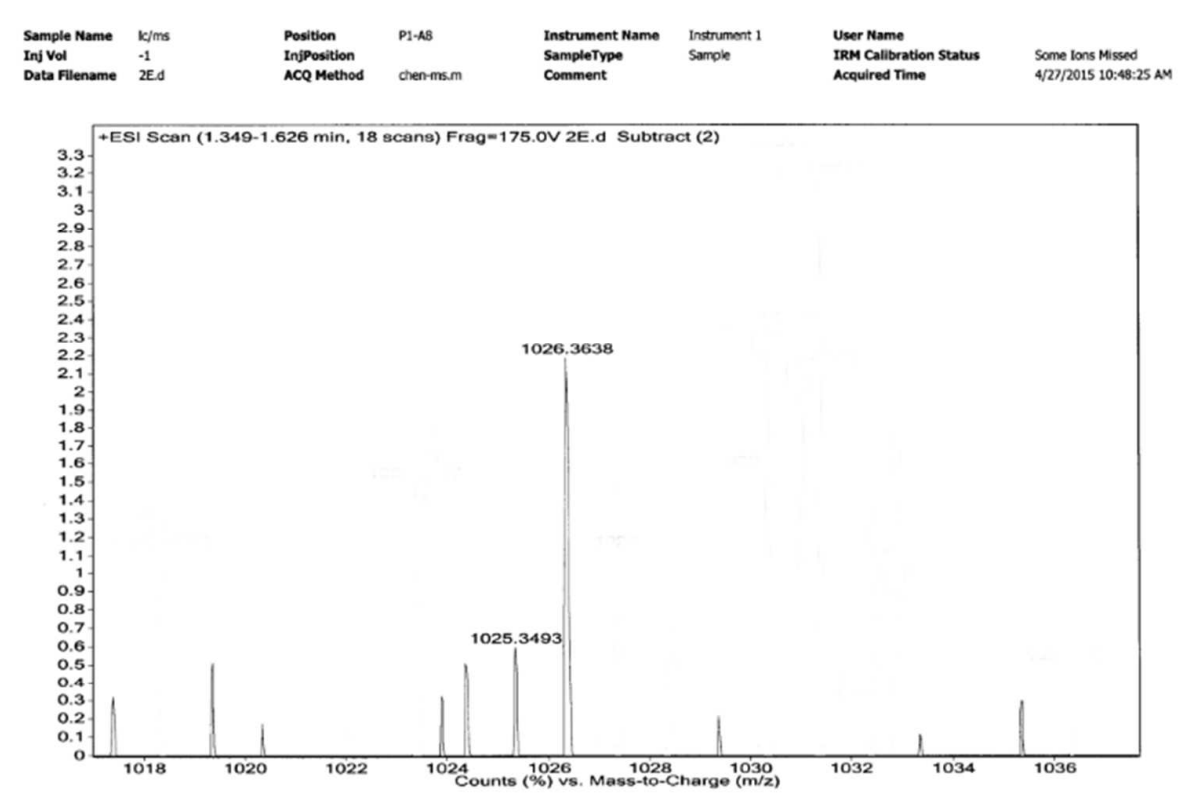

Figure S-13. HR-MS of $\mathrm{N}_{3}$-NTI-FFYEE

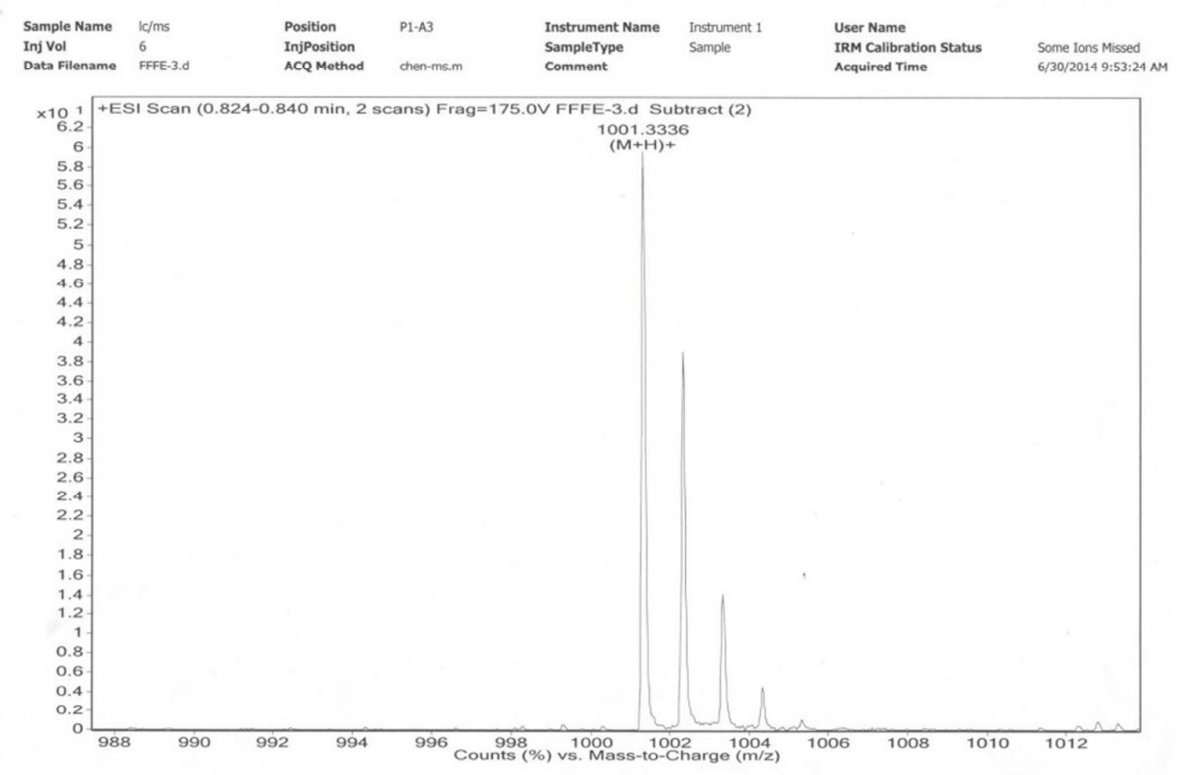

Figure $S$-14.HR-MS of $3 a$ 


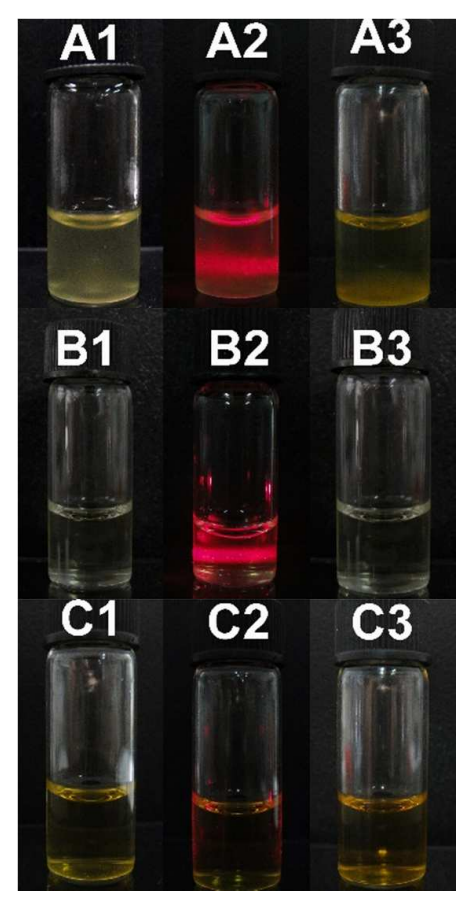

Figure S-15. A1), B1), C1) Optical images of PBS solution of $\mathrm{N}_{3}$-NTI-FFY(100 $\left.\mu \mathrm{M}\right)$, $\mathrm{N}_{3}$-NTI-FFYE $(100 \mu \mathrm{M}), \mathrm{N}_{3}$-NTI-FFYEE $\left.\left.\left.(5 \mathrm{mg} / \mathrm{ml}), A 2\right) ; \mathrm{B} 2\right), \mathrm{C} 2\right)$ the light beam from its solution upon irradiation by a laserpointer; A3), B3), C3) Optical images of PBS solution of $\mathrm{N}_{3}$-NTI-FFY(24h later), $\mathrm{N}_{3}$-NTI-FFYE(1 month later), $\mathrm{N}_{3}$-NTI-FFYEE (1 month later).

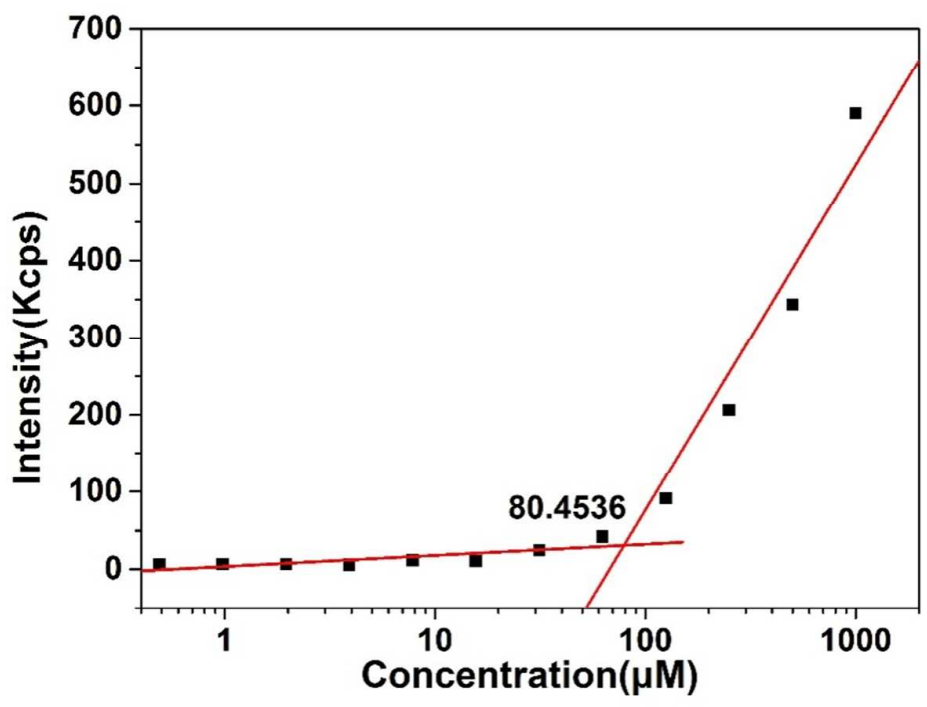

Figure S-16. CMC of compound 1a 


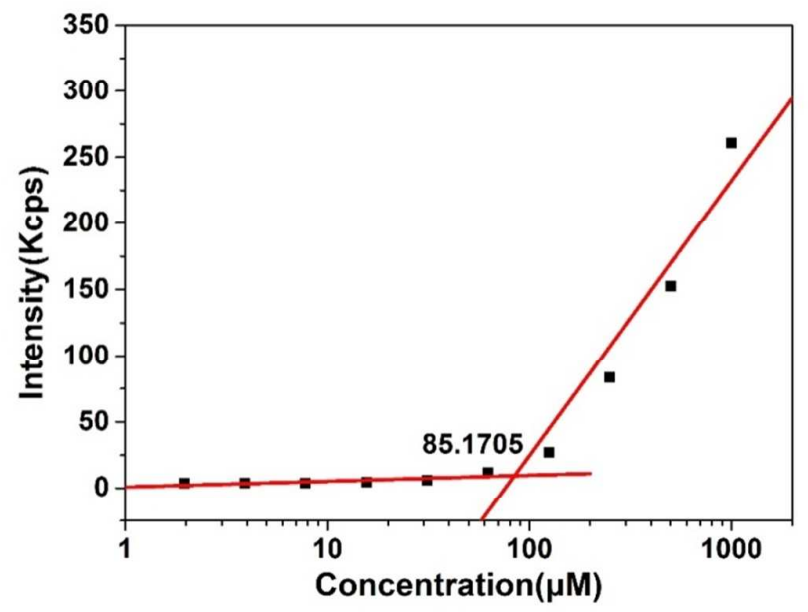

Figure $S$-17. CMC of compound $3 a$
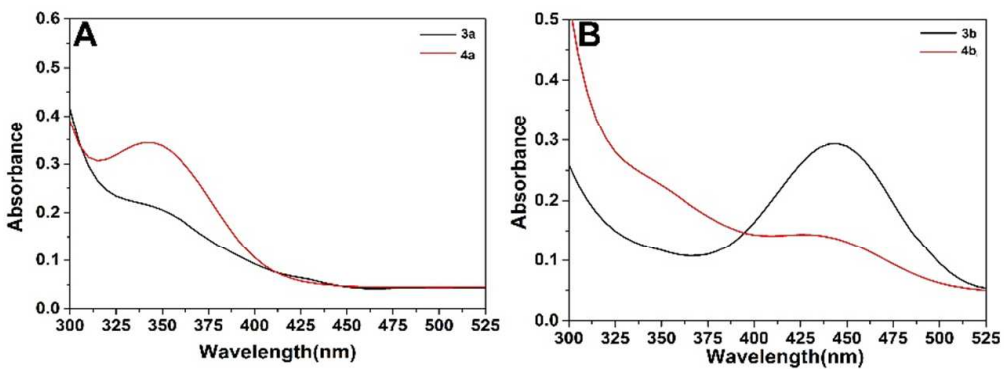

Figure $\boldsymbol{S}$-18. A)The UV-vis spectra of $\mathbf{3 a}$ and $\mathbf{4 a}(100 \mu \mathrm{M}$ in PBS buffer);B) The UV-vis spectra of $3 \boldsymbol{a}$ and $\mathbf{4 a}(100 \mu \mathrm{M}$ in PBS buffer) with $500 \mu \mathrm{M}$ hydrazine.

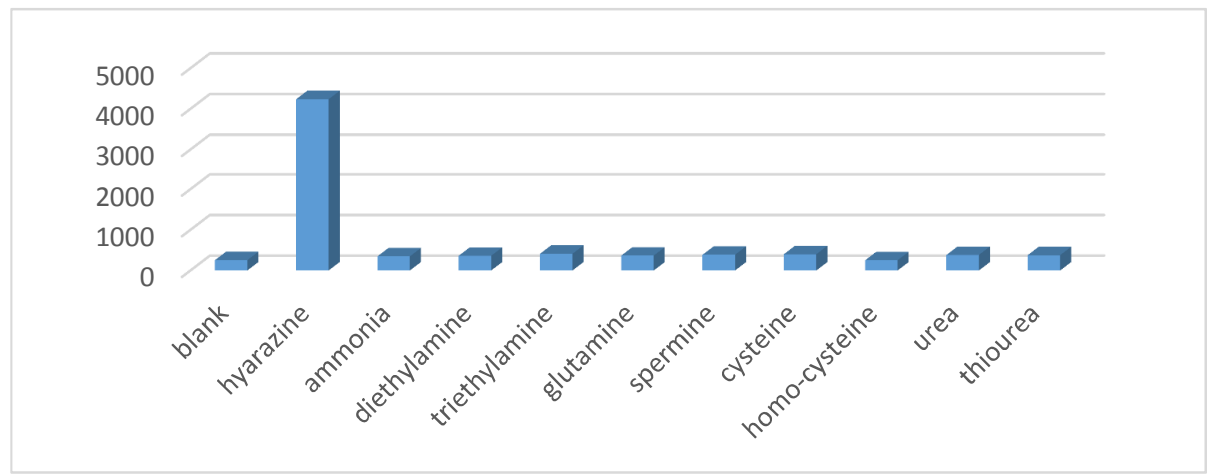

Figure S-19 Fluorescence responses of $3 \boldsymbol{a}(100 \mu \mathrm{M})$ to various species of amines(500 $\mu \mathrm{M})$. Excitation wavelength $=400 \mathrm{~nm}$, the value of ordinate were recorded by the wavelength at $550 \mathrm{~nm}$. 


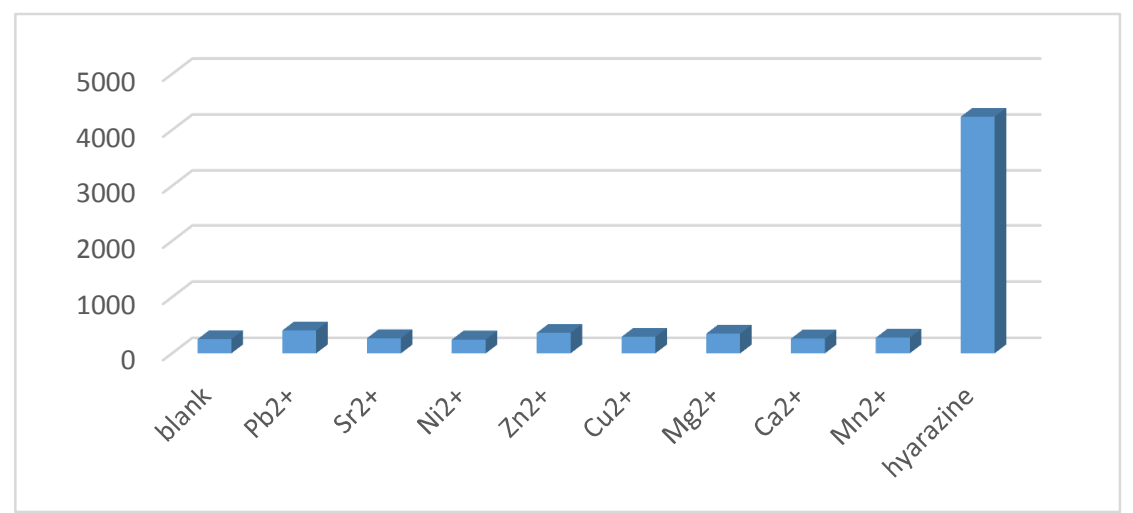

Figure $\mathbf{S - 2 0}$ Fluorescence responses of $\mathbf{3 a}(100 \mu \mathrm{M})$ to various species of metal ions $(500 \mu \mathrm{M})$. Excitation wavelength $=400 \mathrm{~nm}$, the value of ordinate were recorded by the wavelength at 550nm.

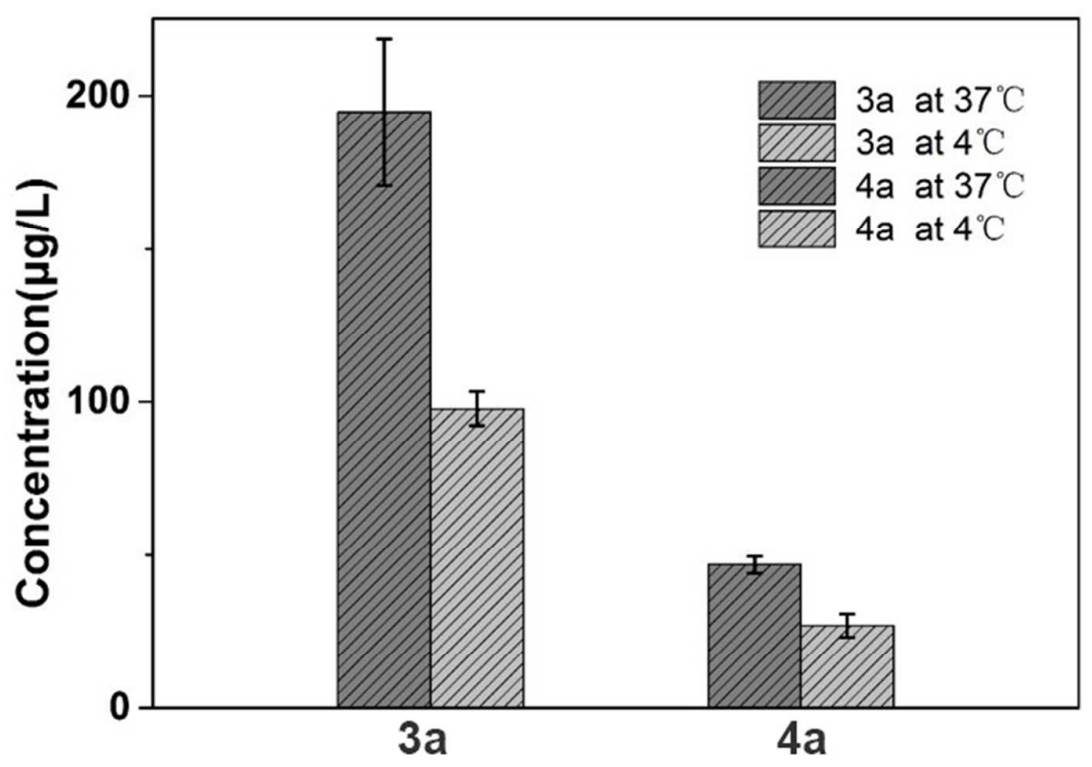

Figure $\boldsymbol{S}$-21. The amount of compound $3 \boldsymbol{a}$ and $\mathbf{4 a}$ within HeLa cells at $4{ }^{\circ} \mathrm{C}$ and $37{ }^{\circ} \mathrm{C}$ determined by LC-MS (the data were expressed as the mean \pm standard error of the mean $(\mathrm{SEM}, \mathrm{N}=3)$ )

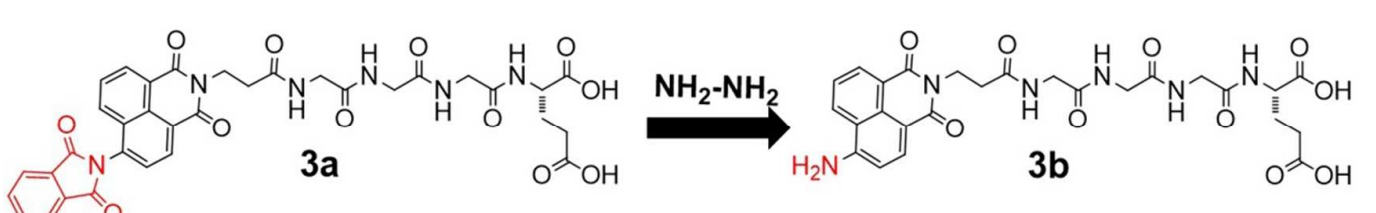

Scheme S-3. Compound $3 c$ to $3 d$ with $\mathrm{N}_{2} \mathrm{H}_{4}$ 


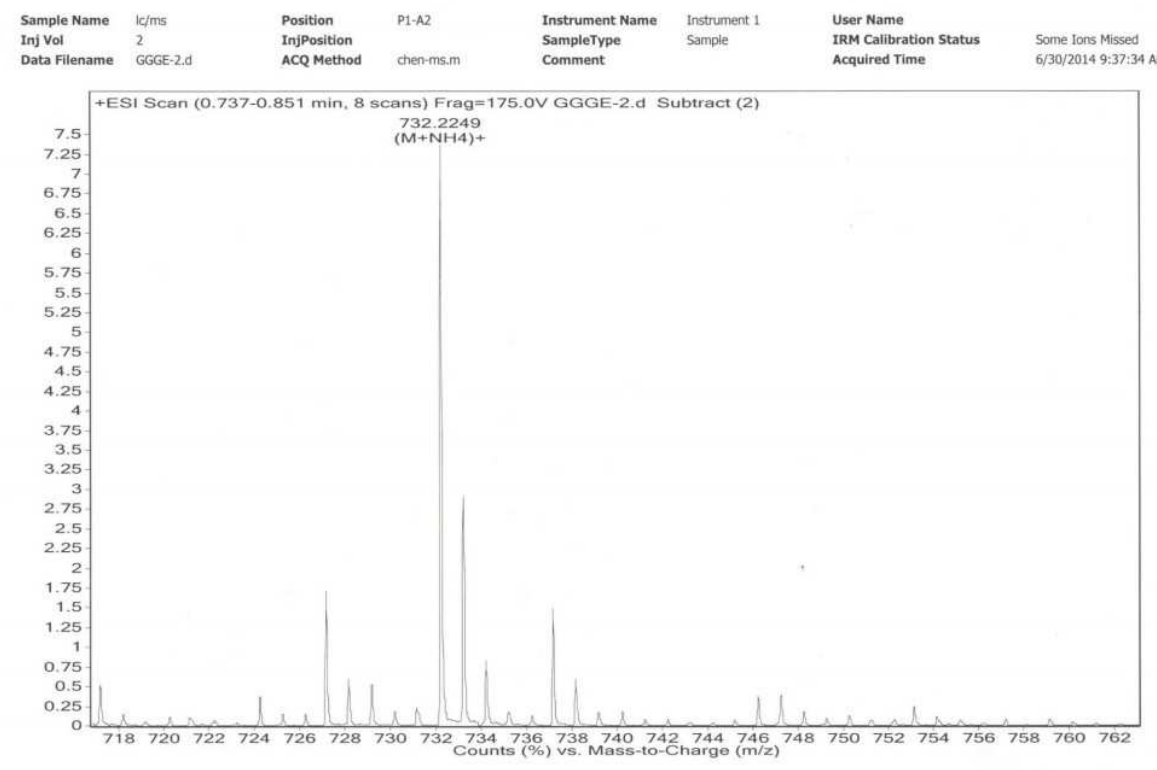

Figure $S$-22 HR-MS of $3 c$
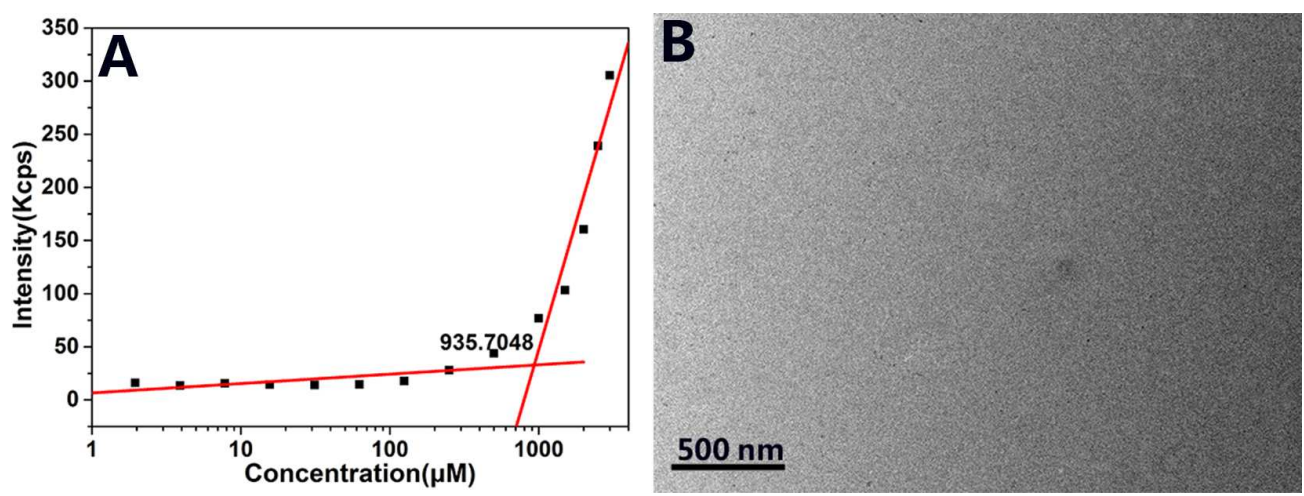

Figure $\mathbf{S - 2 3 .}$ A) CMC of compound $3 \boldsymbol{c}$; B) TEM image of $\mathbf{3 c}$ dissolved in PBS buffer at $100 \mu \mathrm{M}$ 


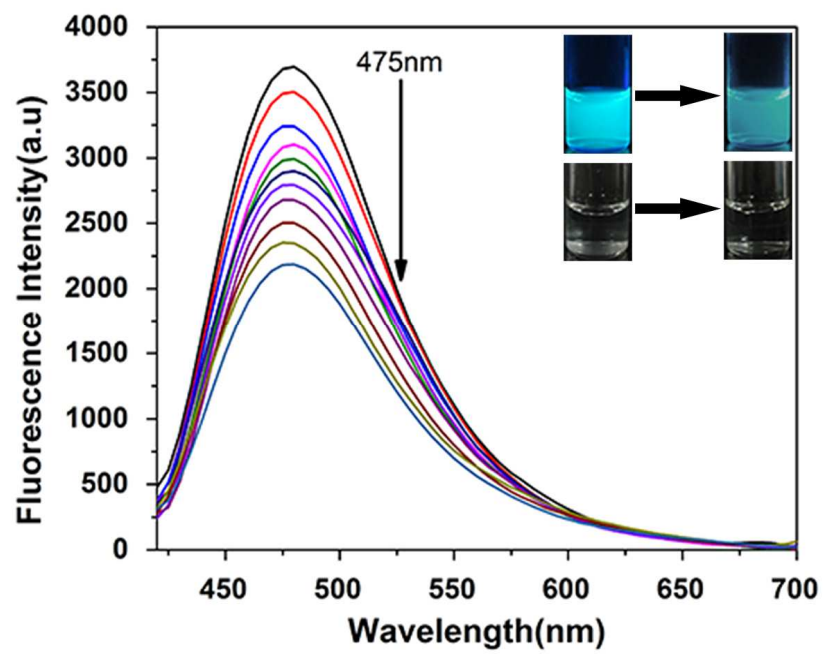

Figure S-24. Fluorescence spectra of solutions of $3 c$ treated with different concentrations of hydrazine (10 to $500 \mu \mathrm{M})$, insets: top) Fluorescence color changes of $3 c$ treated with hydrazine observed using a hand-held UV lamp with an excitation at $330 \mathrm{~nm}$, down) visual color changes of $\mathbf{3 c}$ treated with hydrazine.
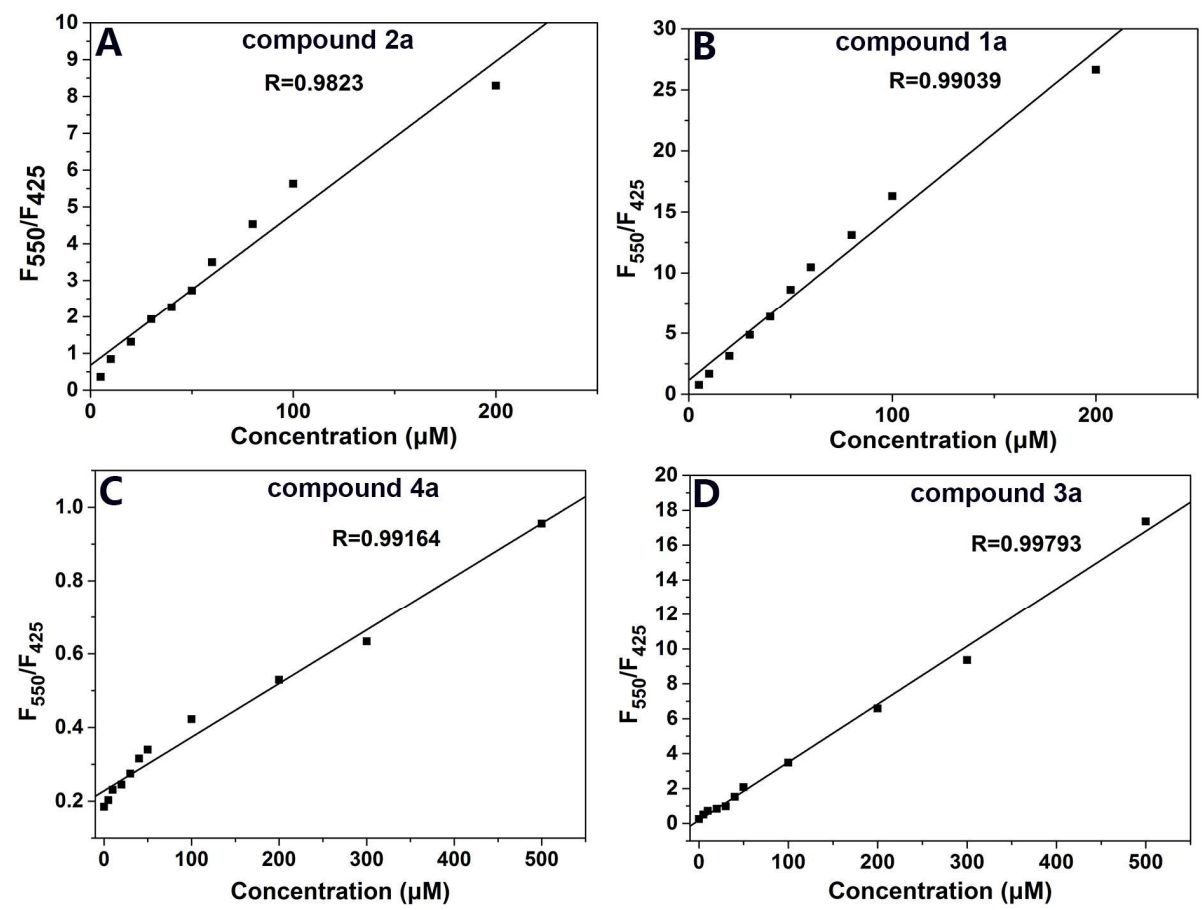

Figure $\mathbf{S - 2 5}$. The fluorescence intensity ratio to different concentration of analyte (1a, $2 \boldsymbol{a}$ with hydrogen sulfide; $\mathbf{3 a}, \mathbf{4} \boldsymbol{a}$ with hydrazine). $\mathbf{1} \boldsymbol{a}, \mathbf{3} \boldsymbol{a}$ was dissolved in PBS buffer at $100 \mu \mathrm{M}$ and $2 a, 4 a$ in PBS buffer with 5\% DMSO at $100 \mu \mathrm{M}$. 


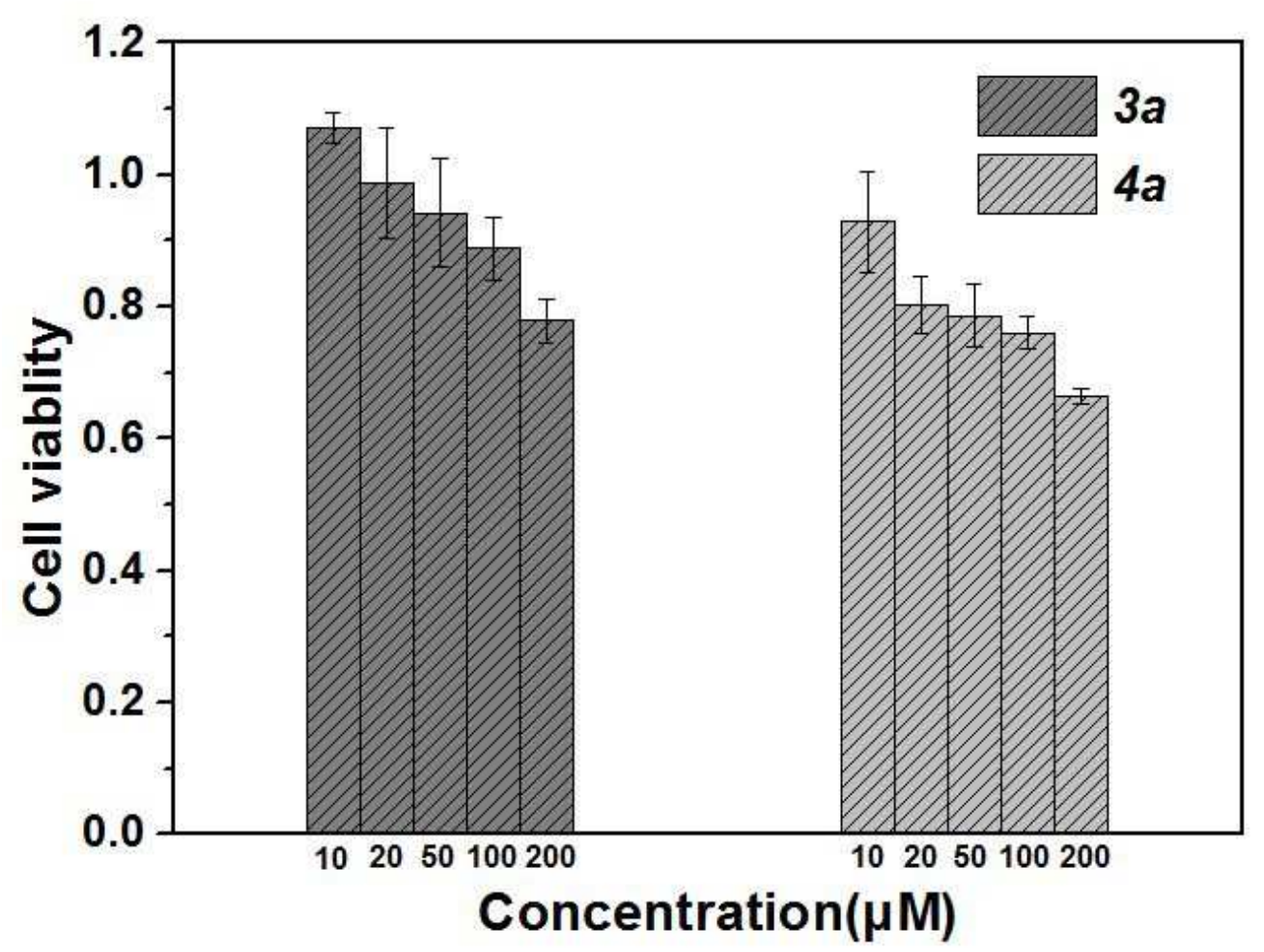

Figure $\mathbf{S - 2 6 .}$. Cell viability of Compound $\mathbf{3 a}$ and $\mathbf{4 a}$ by MTT assay for $24 \mathrm{~h}$. (the data were expressed as the mean \pm standard error of the mean $(\mathrm{SEM}, \mathrm{n}=3)$ ).

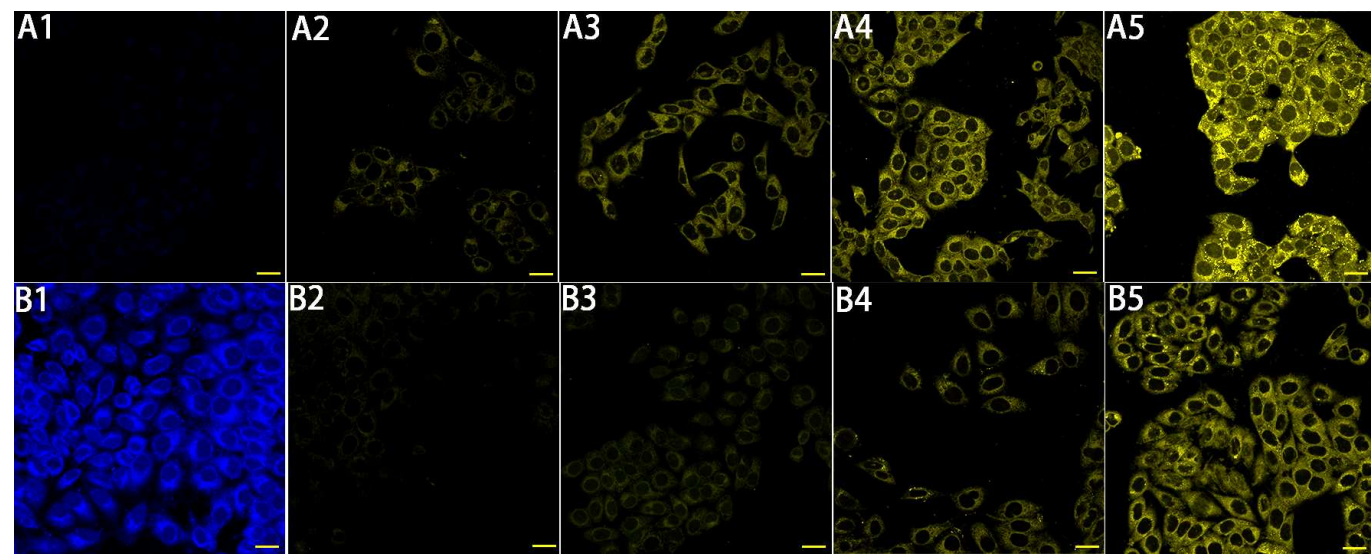

Figure S-27. Confocal fluorescence images of HeLa cells incubated with $100 \mu \mathrm{M}$ of probe A) $3 \boldsymbol{a}$ and B) $4 \boldsymbol{a}$ for $4 \mathrm{~h}$ (blue channel, $\lambda_{\mathrm{abs}}=450 \pm 40 \mathrm{~nm}$ ) and subsequently with different concentration of hydrazine (A2,B2: $10 \mu \mathrm{M}$; A3,B3: $50 \mu \mathrm{M}$; A4,B4: $100 \mu \mathrm{M}$; A5,B5: $200 \mu \mathrm{M}$ ) for another $2 \mathrm{~h}$ (yellow channel, $\lambda_{\mathrm{abs}}=550 \pm 40 \mathrm{~nm}$ ). (Scale bars represent $25 \mu \mathrm{m}, 40 \times)$ 